\title{
THE
}

UNIVERSITY

University of Rhode Island

OF RHODE ISLAND

DigitalCommons@URI

$1-21-2020$

\section{Radiofrequency and Near-Infrared Responsive Core-Shell Nanostructures Using Layersome Templates for Cancer Treatment}

Animesh Pan

University of Rhode Island

Md Golam Jakaria

University of Rhode Island

Samantha A. Meenach

University of Rhode Island, smeenach@uri.edu

Geoffrey D. Bothun

University of Rhode Island, gbothun@uri.edu

Follow this and additional works at: https://digitalcommons.uri.edu/che_facpubs

The University of Rhode Island Faculty have made this article openly available.

Please let us know how Open Access to this research benefits you.

This is a pre-publication author manuscript of the final, published article.

Terms of Use

This article is made available under the terms and conditions applicable towards Open Access

Policy Articles, as set forth in our Terms of Use.

\section{Citation/Publisher Attribution}

Pan, A., Golam, M., Meenach, S. A., \& Bothun, G. D. (2020). ACS Appl. Bio. Mater., 3(1), 273-281.

https://doi.org/10.1021/acsabm.9b00797

Available at: https://doi.org/10.1021/acsabm.9b00797

This Article is brought to you for free and open access by the Chemical Engineering at DigitalCommons@URI. It has been accepted for inclusion in Chemical Engineering Faculty Publications by an authorized administrator of DigitalCommons@URI.For more information, please contact digitalcommons-group@uri.edu. 


\title{
Radiofrequency and Near-Infrared Responsive Core-Shell Nanostructures Using Layersome Templates for Cancer Treatment
}

Animesh Pan ${ }^{1}$, Md Golam Jakarial, Samantha A. Meenach ${ }^{1,2}$, Geoffrey D. Bothun ${ }^{\text {* }}$

${ }^{1}$ Department of Chemical Engineering, University of Rhode Island, Kingston, RI 02881, USA

${ }^{2}$ Department of Biomedical and Pharmaceutical Sciences, University of Rhode Island, Kingston, RI 02881, USA

Keywords: Core-shell nanostructure, gold nanoparticle, liposome, polyelectrolyte, self-assembly.

\begin{abstract}
We report a multifunctional nanotherapeutic platform based on liposomes loaded with drug and iron oxide nanoparticles (IONs) coated with a gold nanoshell synthesized using a polyelectrolyte (layersome) soft templating technique. IONs and gold nanoshells were used to provide combined hyperthermia and triggered drug release via radio frequency (RF) or near-infrared (NIR) stimulation. IONs and the anti-cancer drug doxorubicin (DOX) were co-encapsulated inside liposomes composed of zwitterionic phosphatidylcholine, anionic phosphatidylglycerol, and cholesterol lipids. Coating the magneto-liposomes with positively charged poly-L-lysine enriched the interface with gold anions to form a dense gold nanoshell and protected the structure against deformation and DOX cargo release during shell formation. After modifying with thiol-terminated polyethylene glycol, intracellular delivery and release of DOX from the nanostructures was examined in A549 human lung cancer cells. The nanostructures retained their DOX cargo and
\end{abstract}


remained in the cytosol after cellular uptake. Only when triggered by RF or NIR stimuli did the nanostructures release DOX, which then entered the cell nucleus. Compared to the single photothermal therapy or radio frequency treatment, the carriers with combined DOX and RF or NIR stimulation displayed higher therapeutic effect on A549 cells.

\section{INTRODUCTION}

An incipient challenge in creating nanostructured theranostics is to design "all-in-one" delivery systems that can achieve multiple functions such as stimuli-triggered controlled release, localized hyperthermia treatment, and medical imaging and diagnosis. ${ }^{1-5}$ Inorganic nanoparticles (NPs) have shown great potential as the functional components of theranostics because of their tunable physicochemical and optical properties. ${ }^{6-8}$ Magnetic and plasmonic properties are two extensively studied properties of inorganic NPs, and when combined they provide a range of therapeutic functionalities. ${ }^{8-11}$ Combining these properties within a single nanostructure can be challenging and there are opportunities, through the controlled assembly and synthesis of NP mixtures, to improve the design of colloidally stable multifunctional nanostructures. ${ }^{9}$ This is the case for magnetic core-shell nanoparticles, which have gained particular interest in biomedical research. ${ }^{12}$

Magnetic core-shell NPs are composed of a magnetic particle core surrounded by a shell of inorganic or organic matter. These materials have evolved as an important tool in biomedicine with applications in diagnostics, guided drug delivery, cell sorting, and hyperthermia treatment. ${ }^{13-}$

${ }^{15}$ One such widely studied magnetic core-shell nanostructure uses gold as the shell. ${ }^{16}$ By combining magnetic (iron oxide) and plasmonic (gold) nanoparticles within a single nanostructure, magneto-plasmonic nanoparticles respond to electromagnetic energy spanning frequencies from $\mathrm{kHz}$ (radio frequency or RF) to $\mathrm{THz}$ (near infra-red or NIR). ${ }^{17-21}$ A challenge to creating such 
structures is the ability to control the spatial organization of the materials using biocompatible templates. Liposomes, which are soft nanoscale self-assemblies with hydrophilic and hydrophobic regions, provide a such a template to create these complex colloids. ${ }^{22-24}$ Liposomes have been used extensively for drug encapsulation and controlled release, and there are FDA-approved liposome formulations..$^{21,25-48}$

Biodegradable plasmon resonant nanoshells based on liposomes and gold were first developed by Troutman et al. ${ }^{49}$ They showed that by incorporating gold on the surface of dipalmitoylphosphatidylcholine (DPPC) liposomes, a discontinuous shell was formed that absorbed light in the near NIR region suitable for photothermal mediated drug release. Leung et al. ${ }^{50}$ further showed that upon NIR exposure the lipid membranes were disrupted, allowing the releasing of encapsulated drugs, and the gold shell degraded into 5-10 nm gold nanoparticles. Rengan et al. ${ }^{51,52}$ explored the multifunctional capabilities of their liposome/gold-based nanostructures in a small animal model and demonstrated shell degradation within hepatocytes, and further clearance through the hepato-biliary and renal route. Attempts to control shell structure have included adding glutathione, ${ }^{53}$ chitosan, ${ }^{25}$ and poly-L-lysine ${ }^{24}$ to modify the liposome surface and increase its affinity for gold to form a continuous shell as opposed to discrete nanoparticles. Finally, additional motivation for designing hybrid magneto-plasmonic liposomes has been demonstrated by Tomitaka et al. ${ }^{20,21}$ for image-guided HIV treatment. They reported high drug loading within the liposomes, greater passage through the blood brain barrier (BBB), and precise monitoring of drug distribution using multi-modal imaging.

We have developed a multifunctional nanoplatform composed of an anionic magnetoliposomes $[\mathrm{ML}]$ layered with a cationic polyelectrolyte $\left[\mathrm{ML}_{\mathrm{P}}\right]$ to form a gold nanoshell $\left[\mathrm{ML}_{\mathrm{PG}}\right]$ that was conjugated with a $2000 \mathrm{MW}$ polyethylene glycol thiol, PEG-[MLPG] (Scheme 1). In 
contrast to prior core-shell magneto-plasmonic nanostructures, the PEG-[MLPG] particles are spatially separated within a lipid bilayer/poly-L-lysine layersome that enriches the surface with anionic gold precursor ions. The separation stabilizes the structure by preventing direct contact between the gold nanoshell and the membrane barrier used to entrap cargo. We report herein on the design and characterization of the core-shell nanostructures, the ability to heat and trigger drug release using radiofrequency (RF) or NIR laser stimuli, and the ability to achieve stimuliresponsive intracellular drug delivery to a model cancer cell line, A549 lung cancer cells.

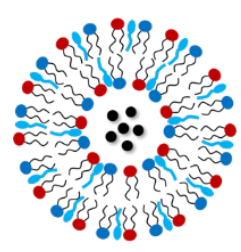

[ML]

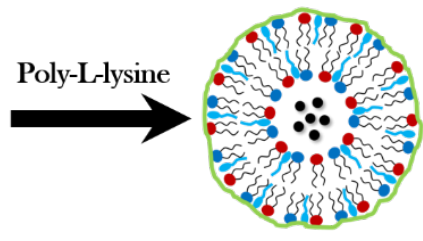

$\left[\mathrm{ML}_{\mathrm{P}}\right]$

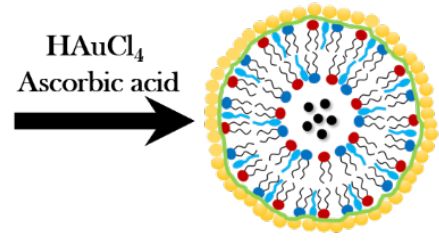

$\left[\mathrm{ML}_{\mathrm{PG}}\right]$

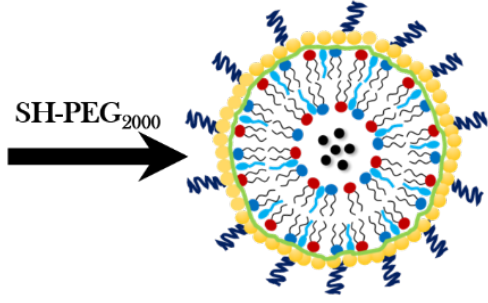

PEG-[ML $\left.\mathrm{MG}_{\mathrm{PG}}\right]$

ION

DOPC $\cong$ DOPG

Chol

on Poly-L-lysine

GNP

SHPEG2000 WW

Scheme 1. Liposome templated multifunctional core-shell nanostructures. Magneto-liposomes, $[\mathrm{ML}]$ are coated with poly-L-lysine, $\left[\mathrm{ML}_{\mathrm{P}}\right]$ upon which a gold nano-shell is formed, $[\mathrm{ML} \mathrm{PG}]$. The nanoshell surface is functionalized with 2000 MW PEG-thiol, PEG-[MLPG]. Additional abbreviations: iron oxide nanoparticle (ION), gold nanoparticle (GNP), 1,2-dioleoyl-sn-glycero3-phosphocholine (DOPC), 1,2-dioleoyl-sn-glycero-3-phospho-(1'-rac-glycerol) (sodium salt) (DOPG), PEG-thiol (SHPEG2000), and cholesterol (Chol).

\section{EXPERIMENTAL SECTION}

\section{Materials}

DOPC (1,2-Dioleoyl-sn-glycero-3-phosphocholine) and DOPG (1,2-dioleoyl-sn-glycero-3phospho-(1'-rac-glycerol) (sodium salt)) were purchased from Avanti Polar lipids (Alabaster, AL 
USA). Poly-L-lysine hydrochloride (PLL, MW = 15,000-30,000), tetrachloroauric acid trihydrate $\left(\mathrm{HAuCl}_{4} \bullet 3 \mathrm{H}_{2} \mathrm{O}\right)$, poly(ethylene glycol) methyl ether thiol $\left(\mathrm{SH}_{-} \mathrm{PEG}_{2000}\right)$, average $\left.\mathrm{MW}=2,000\right)$, doxorubicin (DOX), and cholesterol (Chol) were obtained from Sigma Aldrich (St. Louis, USA). Anionic (carboxyl) superparamagnetic iron oxide nanoparticles (SPIONs, $15 \mathrm{~nm}$ core diameter) were purchased from Ocean Nanotech, LLC, San Diego, USA. Tris(hydroxymethyl)aminomethane and ascorbic acid (AA) were purchased from Thermo Fisher Scientific. A Millipore water system (Direct Q @ UV) provided high purity of water that used for all experiments. A549 human lung adenocarcinoma epithelial cells were obtained and cultured as previously described. ${ }^{54}$

\section{Preparation of [MLP] and [MLP-DOX]}

[ML] were prepared by the reverse-phase evaporation method ${ }^{55,56}$ with slight modification. A mixture of DOPC/DOPG/Chol (50:40:10 molar) was dissolved in $4 \mathrm{~mL}$ of chloroform, and $1 \mathrm{~mL}$ aqueous dispersion of IONs $\left(5 \mathrm{mg} \mathrm{mL}^{-1}\right)$ was introduced before sonication at room temperature for 10 min to produce a water-in-oil emulsion. Liposomes [L] were also prepared without IONs as a negative control sample for RF heating. For DOX encapsulation [ML-DOX], the aqueous dispersion also contained DOX at $0.2 \mathrm{mg} \mathrm{mL}^{-1}$. The mixtures were immediately transferred to a round-bottom flask and the organic solvent was evaporated using a rotavapor R-215 (Buchi) at 40 ${ }^{\circ} \mathrm{C}$ with pressure ranging from 100 to $450 \mathrm{mbar}$ for $2 \mathrm{~h}$ until a gel-like dispersion was formed. Deionized water was added to the gel to replenish what was lost during evaporation. To remove trace solvent, the samples were again subjected to evaporation for $10 \mathrm{~min}$ at $50 \mathrm{mbar}$ and $40^{\circ} \mathrm{C}$. At this point, the gel completely collapsed and [ML] or [ML-DOX] were formed. Samples were centrifuged at $100 \mathrm{~g}$ for $3 \mathrm{~min}$ to remove any large aggregates, and the supernatant was then 
extruded sequentially using $400 \mathrm{~nm}$ and $200 \mathrm{~nm}$ polycarbonate track-etched membranes. The samples were centrifuged again at $1000 \mathrm{~g}$ for $25 \mathrm{~min}$ to remove unencapsulated DOX and IONs.

$[\mathrm{ML}]$ or $[\mathrm{ML}-\mathrm{DOX}]$ were coated with poly-L-lysine by adding them dropwise to $0.5 \mathrm{mg}$ $\mathrm{mL}^{-1}$ of PLL in deionized water and then stirring and resting for $30 \mathrm{~min}$ at room temperature. The [MLP] or $\left[\mathrm{MLP}_{\mathrm{P}} \mathrm{DOX}\right]$ were centrifuged for $25 \mathrm{~min}$ at $1000 \mathrm{~g}$ to remove the excess PLL from solution. The resuspended samples were stored at $4{ }^{\circ} \mathrm{C}$ until further use.

\section{Preparation of PEG-[MLPG] and PEG-[MLPG-DOX]}

To form nanoshells, $200 \mu \mathrm{L}$ of $\mathrm{HAuCl}_{4}$ aqueous solution $(25 \mathrm{mM})$ was added to a [MLP] or [MLPDOX] dispersion. Ascorbic acid solution $(200 \mu \mathrm{L}, 50 \mathrm{mM})$ was added and mixed for 5 min to complete the reduction. The resulting $\left[\mathrm{ML}_{\mathrm{PG}}\right]$ or $\left[\mathrm{ML}_{\mathrm{PG}}-\mathrm{DOX}\right]$ structures were added to a solution of SH-PEG $2000\left(12.5 \mathrm{mg} \mathrm{mL}^{-1}\right)$, vortex mixed and centrifuged, and washed multiple times at $1000 \mathrm{~g}$ for $25 \mathrm{~min}$ to remove the unbound $\mathrm{SH}-\mathrm{PEG}_{2000}$. The final samples were stored at $4{ }^{\circ} \mathrm{C}$. Au and $\mathrm{Fe}$ concentrations were determined by inductively coupled plasma mass spectrometry (ICP-MS) analysis (Thermo X-Series 2 with a New Wave UP123 Nd-YAG laser ablation system).

\section{Nanostructure Characterization}

The size and surface charge (zeta potential) were determined by dynamic light scattering measurements using a Malvern Zetasizer Nano-ZS (Worcestershire, United Kingdom) equipped with a backscattering detector angle of $173^{\circ}$ and a $4 \mathrm{~mW}, 633 \mathrm{~nm} \mathrm{He}-\mathrm{Ne}$ laser. The z-averaged hydrodynamic radii and zeta potentials reported are based on triplicate measurements each with 10 scans. The morphology of the nanostructure's assemblies was examined by cryogenic transmission electron microscopy (Cryo-TEM; JEOL JEM-2100F TEM, Peabody, MA) operating 
at $200 \mathrm{kV}$ using a liquid nitrogen cooling stage (Model 915, Gatan Inc., Pleasanton, CA). Specimens were prepared by depositing $10 \mu \mathrm{L}$ of sample onto a Quantfoil copper grid with a 200 square mesh overlaid with a $2 \mu \mathrm{m}$ holey carbon layer (Electron Microscopy Sciences, Hatfield, PA). The sample grids were vitrified in liquid ethane using a Vitrobot (FEI Company, Hillsboro). For regular TEM samples, specimens were prepared by placing a drop of the sample onto a carboncoated copper grid with 300 mesh and slow drying under vacuum.

\section{Radiofrequency Heating}

RF-heating experiments were conducted using an RF generator (Hotshot ${ }^{\mathrm{TM}}$, Ameritherm Inc., Scottsville, New York) with an 8-turn copper coil with an inner diameter of $2.54 \mathrm{~cm}$ placed around a thermally isolated sample glass vial. Power was supplied at $1 \mathrm{~kW}$ with a frequency of $368 \mathrm{kHz}$ and an amplitude of $160 \mathrm{~A}$. Bulk temperature was monitored using an infrared thermal imaging camera (FLIR Ax5 camera). Specific absorbance rates (SAR) were determined from measured heat generation (energy dissipation) after subtracting the effect of RF-heating of water in the absence of nanoparticles, $d\left(T-T_{\text {water }}\right) / d t$, using equation $1^{57}$

$\operatorname{SAR}\left(\frac{w}{g}\right)=\frac{C_{p}}{m_{M N P}} \times \frac{d\left(T-T_{w a t e r}\right)}{d t}$

where $c_{p}$ is the weighted specific heat capacity of the medium $\left(4.2 \mathrm{~J} \mathrm{~g}^{-1}{ }^{\circ} \mathrm{C}^{-1}\right)$, and $m_{M N P}$ is the concentration $\left(\mathrm{g} \mathrm{L}^{-1}\right.$ of $\left.\mathrm{Fe}\right)$ of magnetic material in solution. The calorimetric measurements were carried out in quasi-adiabatic conditions, and the initial slope of the curve $d\left(T-T_{\text {water }}\right) / d t$ was measured over the first $100 \mathrm{~s}$ of stimulation.

\section{Photothermal Heating}


NIR photothermal heating was conducted by irradiating samples at $785 \mathrm{~nm}$ laser (power density $\left.3.5 \mathrm{~W} \mathrm{~cm}^{-2}\right)$ source $(\mathrm{BWF} 1-785-450 \mathrm{E} / 55371)$ for $10 \mathrm{~min}$. Temperature was monitored using a thermocouple (Personal Daq View) fitted to the side of the vial.

Photothermal conversion efficiency $(\eta)$ was determined as previously reported ${ }^{58,59}$

$\eta=\frac{h S\left(T_{\max }-T_{\infty}\right)-Q_{d i s}}{I\left(1-10^{\left.-A_{785}\right)}\right.}$

where $h$ is the heat transfer coefficient, $S$ is the surface area of the vial, $T_{\max }$ is the maximum steady-state temperature of the sample solution $\left(43.8{ }^{\circ} \mathrm{C}\right.$ for PEG-[MLPG]), $T_{\infty}$ is the ambient surrounding temperature $\left(25^{\circ} \mathrm{C}\right), Q_{d i s}$ is the heat dissipated from the light absorbed by the water and container, $I$ is the laser power, and $A_{785}$ is the absorbance of the sample solution at $785 \mathrm{~nm}$ (1.015 for PEG-[MLPG]). The same experiment was conducted with water as a control to determine $Q_{\text {dis }}(\mathrm{mW})$.

$Q_{\text {dis }}=h S\left(T_{\max }-T_{\infty}\right)_{\text {water }}$

The term $h S$ was calculated based on

$h S=\frac{m c_{p}}{\tau_{S}}$

where $\tau_{s}$ is the sample system time constant and $m$ is the mass $(0.5 \mathrm{~g})$ and $c_{p}$ is the heat capacity $\left(4.2 \mathrm{~J} \mathrm{~g}^{-1}{ }^{\circ} \mathrm{C}^{-1}\right)$ of water. $\tau_{s}$ is related to a dimensionless driving force temperature $\theta$ by

$t=-\tau_{s} \ln \theta$

where $t$ is the cooling time and $\theta$ the dimensionless temperature.

$\theta=\left(T-T_{\infty}\right) /\left(T_{\max }-T_{\infty}\right)$

The time constant for heat transfer from our system was determined to be $\tau_{\mathrm{s}}=173.2 \mathrm{~s}$ by applying the liner time data from the cooling period (after $10 \mathrm{~min}$ ) vs $-\ln \theta$. Using equation (4), $h S$ was calculated to be $12.1 \mathrm{~mW}^{\circ} \mathrm{C}^{-1}$. 


\section{Drug Encapsulation and Stimuli Responsive Release}

The encapsulation efficiency of DOX was determined by adding $2 \mathrm{wt} \%$ Triton X-100 to solubilize [ML-DOX]. DOX concentration was determined by fluorescence spectrophotometer (PerkinElmer LS55, Waltham MA, USA) at excitation and emission wavelength of $484 \mathrm{~nm}$ and $598 \mathrm{~nm}$, respectively. The encapsulation efficiency was calculated as (weight of loaded drug) / (weight of initially added drug) $\times 100 \%$.

DOX release was examined with and without RF or NIR stimuli. PEG-[MLPG-DOX] dispersions $(1 \mathrm{~mL})$ were transferred to dialysis bags (Float-A-Lyzer G2; MWCO: 8-10 kDa) after preparation and immersed in Tris- $\mathrm{HCl}$ buffer dialysate $(10 \mathrm{mM} \mathrm{NaCl}$ of $\mathrm{pH} 7.4)$. Dialysate samples $(0.2 \mathrm{~mL})$ were collected and fresh Tris- $\mathrm{HCl}$ buffer was added to the dialysate reservoir to maintain a constant volume. The concentration of DOX in the dialysate was measured by fluorescence spectroscopy.

\section{In Vitro Cell Studies}

Cell Culture and Cell Cytotoxicity. A549 cells were cultured in Dulbecco's modified Eagle's medium (DMEM) with $1 \mathrm{mM}$ sodium pyruvate, $1 \%$ penicillin-streptomycin, and 10\% Fetal bovine serum (FBS) at $37{ }^{\circ} \mathrm{C}$ in a humidified incubator. Cytotoxicity studies were carried out using the MTT ((3-(4,5-dimethylthiazol-2-yl)-2,5-diphenyltetrazolium bromide)) assay. ${ }^{60}$ A549 cells were seeded into 96-well plates at a concentration of $10^{4}$ cells per well. After $48 \mathrm{~h}$, the media was discarded and free DOX and PEG-[MLPG-DOX] were diluted in fresh media and added $(200 \mu \mathrm{L})$

to the wells in at $0.67 \mu \mathrm{g} \mathrm{mL}^{-1}$ to $6.7 \mu \mathrm{g} \mathrm{mL}^{-1}$ free and encapsulated DOX. Cells were incubated with these treatments for $48 \mathrm{~h}$. Following incubation, the cells were rinsed twice with PBS and 
then incubated with $200 \mu \mathrm{L}$ of MTT $\left(5 \mathrm{mg} \mathrm{mL}^{-1}\right)$ at $37{ }^{\circ} \mathrm{C}$ and $5 \% \mathrm{CO}_{2}$ under light protection. After $1 \mathrm{~h}$, MTT was removed from each well and DMSO (100 $\mu \mathrm{L})$ was added to dissolve the purple crystals. The plates were gently shaken for $10 \mathrm{~min}$ at room temperature and the absorbance was measured using a multi-mode microplate reader (SpectraMax M2) at $540 \mathrm{~nm}$. Relative cell viability was calculated as a percentage compared to untreated control cells (Sample Absorbance/Control Absorbance x 100\%). In vitro experiments were conducted in triplicate.

For in vitro studies combining DOX delivery and photothermal treatment, A549 cells in 96-well plates were irradiated with a $785 \mathrm{~nm}$ laser for $10 \mathrm{~min}$ at a power of $450 \mathrm{~mW}$ after the initial $4 \mathrm{~h}$ of incubation. The cells were then incubated for $48 \mathrm{~h}$ and the MTT assay was conducted as described above. A parallel set of experiments was carried out under similar conditions without laser irradiation.

In vitro studies combining DOX delivery and RF treatment were conducted using 6 well plates seeded with $5 \times 10^{5}$ A549 cells per well that were incubated with cell media containing PEG[MLPG-DOX]. The wells were washed three times with $2 \mathrm{~mL}$ of $1 \mathrm{x}$ PBS, and the cells were detached with trypsin $(0.5 \mathrm{wt} \%)$ and suspended in $2 \mathrm{~mL}$ of culture media. The suspension was added to a $5 \mathrm{~mL}$ glass vial and placed inside the RF coil prior to exposure to the RF field for 30 min. Following RF treatment, cells were seeded in 96 well plates in $200 \mu \mathrm{L}$ of cell culture media (approximately $10^{4}$ cells per well) for $48 \mathrm{~h}$. Cells were then washed once with $1 \mathrm{x}$ PBS (100 $\mu \mathrm{L}$ per well) and evaluated by the MTT assay.

Cell uptake. A549 cells were seeded in a 96-well plate at $10^{4}$ cells per well and incubated over night at $37{ }^{\circ} \mathrm{C}$. The media was discarded, and the cells were incubated with PEG-[MLPGDOX] for $2 \mathrm{~h}$ and $4 \mathrm{~h}$. The cells were washed three times with PBS to remove unbounded particles, and the cells were trypsinized by adding $100 \mu \mathrm{L}$ of trypsin-EDTA. The trypsinized cells were then 
analyzed by ICP-MS to determine the amount of iron and gold taken up by the cancer cells. In order to visually check particle uptake, confocal microscopy analysis was performed.

Confocal Laser Scanning Microscopy (CLSM). A549 cells were seeded and grown in 35 mm glass bottom Petri dishes (Mattek) at $5 \times 10^{5}$ cells/dish overnight at $37{ }^{\circ} \mathrm{C}$ and $5 \% \mathrm{CO}_{2}$. DOX and PEG-[MLPG-DOX] were dispersed in cell medium and incubated with cells. After $4 \mathrm{~h}, \mathrm{DOX}$ and PEG-[MLPG-DOX] were removed, and the cells were washed three times with PBS and then incubated in media containing Cell Mask Deep Red (Invitrogen) at $0.5 \mu \mathrm{g} \mathrm{mL}-1$ media for $5 \mathrm{~min}$. The cells were then fixed with $4 \%$ paraformaldehyde for $10 \mathrm{~min}$, rinsed three times with PBS, and the nuclei were stained with DAPI (Invitrogen). Fresh PBS was added to the samples, and the cells were imaged using a Nikon Eclipse Ti2 inverted confocal fluorescent microscope.

To confirm the localized photothermal and RF effect of PEG-[MLPG-DOX] cells were incubated with nanostructures for $2 \mathrm{~h}$ at $37{ }^{\circ} \mathrm{C}$ and $5 \% \mathrm{CO}_{2}$ and were then washed with PBS three times before RF or NIR stimuli. The solutions were stimulated by RF for 30 min or by NIR for 10 min. After stimuli was applied, the cells were incubated for $2 \mathrm{~h}$ at $37^{\circ} \mathrm{C}$ and imaged by confocal fluorescence microscopy as described previously.

Inductively Coupled Plasma Mass Spectrometry (ICP-MS). ICP-MS was used for quantitative elemental analysis of the core-shell nanomaterials in bulk and to confirm in vitro internalization of nanostructures. Prior to elemental analysis, samples were digested with a mixture of $\mathrm{HCl}$ and $\mathrm{HNO}_{3}(1: 3 \mathrm{v} / \mathrm{v})$ overnight and treated with $\mathrm{H}_{2} \mathrm{O}_{2}$ at $90{ }^{\circ} \mathrm{C}$ for $2 \mathrm{~h}$. The sample volume was adjusted with $2 \% \mathrm{HNO}_{3}$ and the elemental content was analyzed using ICP-MS (Thermo XSeries 2 with a New Wave UP123 Nd-YAG laser ablation system).

Statistical Analysis. Experimental results are expressed as the mean \pm standard deviation three independent experiments. Unpaired, two-tailed t-tests were used to evaluate significant 
differences between a pair of groups. Levels of significance were $\mathrm{p}<0.05(*), \mathrm{p}<0.01(* *)$ and $\mathrm{p}$ $<0.001(* * *)$. The statistical analysis was completed using OriginPro 2019 software. Image analysis was performed using Image $\mathrm{J}$ software.

\section{RESULTS AND DISCUSSION}

\section{Nanostructure Characterization}

PEG-[MLPG] were prepared by (1) encapsulating IONs within liposomes, ${ }^{56}$ (2) coating the resulting magneto-liposomes with cationic poly-L-lysine, (3) reducing the gold to form a gold nanoshell, and (4) modifying the nanoshell with PEG-thiol The nanostructures were characterized by DLS after steps (1), (2), and (4) (Figure 1A, B). After each step, the hydrodynamic diameter of the structures increased, and the charge inverted, reflecting a change in surface composition. From these measurements, the GNS thickness was $\sim 16 \mathrm{~nm}$ and the effective PEG-thiol coating thickness was $\sim 12 \mathrm{~nm}$. PEG-[MLPG] exhibited a broad absorbance peak with a maximum at $696 \mathrm{~nm}$ (Figure 1C). In contrast, gold NPs (GNPs) formed at the same condition in the absence of a liposome template exhibited a sharp peak at $521 \mathrm{~nm}$. Collectively, these results confirm that the synthesis process yielded core-shell nanostructures active in the NIR region.
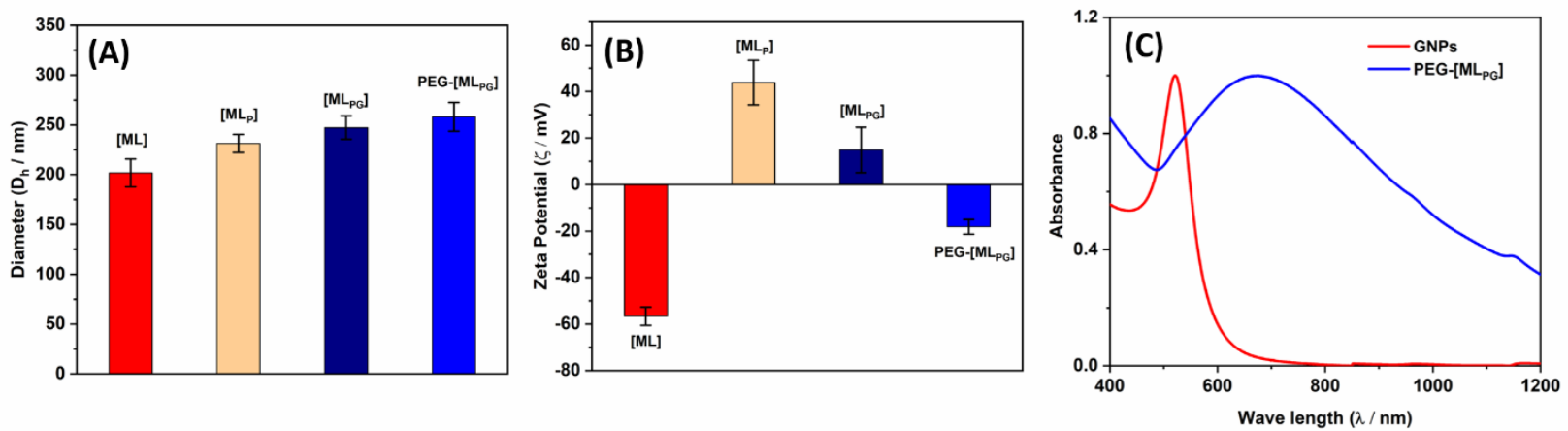
Figure 1. Nanostructure characterization. (A) Hydrodynamic diameter; (B) zeta potential of [ML], [MLP], [MLPG], PEG-[MLPG]; and (C) UV-vis spectra of GNPs and PEG-[MLPG]. All measurements were performed in deionized water.

Direct evidence of PEG-[MLPG] formation was obtained by TEM with representative images shown in Figure 2 depicting ION encapsulation (Figure 2A) and GNS formation (Figure 2B, C). The presence of iron oxide (as $\mathrm{Fe}$ ) and gold at each step of the process, and their co-localization in the final structure, were confirmed by energy dispersive x-ray spectroscopy (EDS) (Figure 2D) and ICP-MS analysis. The final compositions of the PEG-[ML $\left.L_{\mathrm{PG}}\right]$ and PEG-[ML $\left.L_{\mathrm{PG}}\right]$ nanostructures are shown in Table 1.
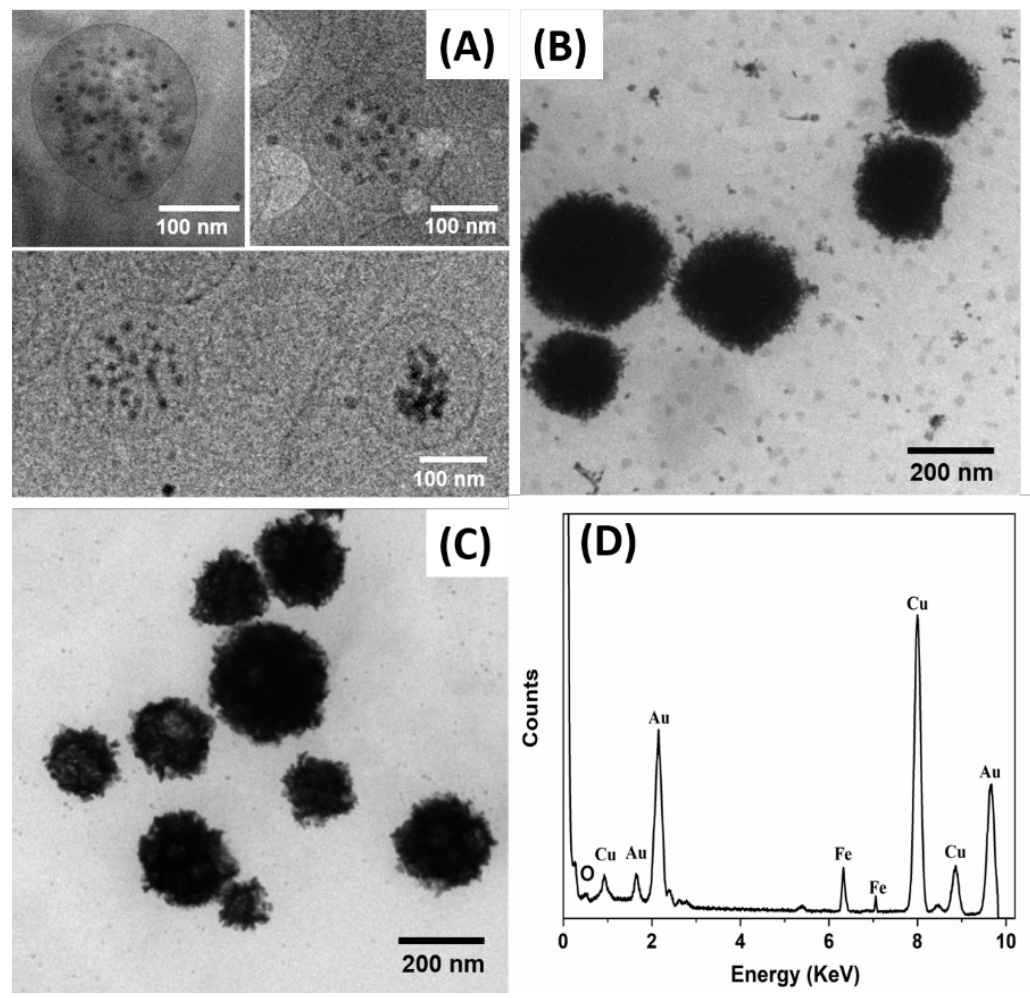

Figure 2. Electron microscopy (EM). (A) Cryo-TEM images of magnetoliposomes (ML); (B) TEM images of core-shell (IONs in core and gold on shell) nanostructures [ML $\mathrm{PG}_{\mathrm{PG}}$; and (C) TEM 
images of SH-PEG 2000 coated core-shell aggregates PEG-[MLPG]. (D) Energy dispersive x-ray spectroscopy (EDS) spectra for PEG-[MLPG].

Table 1. PEG-[MLPG-DOX] nanostructure composition.

\begin{tabular}{ll}
\hline Material & Concentration \\
\hline Total lipid & $2 \mathrm{mg} \mathrm{mL}^{-1}$ \\
Iron oxide nanoparticles (IONs) ${ }^{1}$ & $376 \mu \mathrm{g} \mathrm{mL}^{-1}$ \\
Poly-L-lysine (PLL) & $500 \mu \mathrm{g} \mathrm{mL}^{-1}$ \\
Gold & $181 \mu \mathrm{g} \mathrm{mL}^{-1}$ \\
Doxorubicin (DOX) $^{1}$ & $6.7 \mu \mathrm{g} \mathrm{mL}^{-1}$ \\
${ }^{1}$ equivalent concentration of encapsulated components based on ICP-MS (Fe) or fluorescence \\
spectroscopy (DOX) \\
${ }^{2}$ equivalent amount of gold on the shell based on ICP-MS
\end{tabular}

\section{Radio Frequency Heating}

Brownian (viscous) and Néel (dipolar) relaxation mechanism are responsible for heating ION dispersions in a RF field. RF heating was evaluated for nanostructures with and without gold or iron oxide nanoparticles to obtain SAR values ${ }^{61}$ (Figure 3A). Nanostructures without IONs, PEG$\left[\mathrm{LPG}_{\mathrm{PG}}\right]$, generated heat when compared to the water control sample consistent with reports that gold nanoparticles can be heated in RF fields at similar frequencies. ${ }^{62,63}$ However, only when IONs were encapsulated was significant heat generated. Furthermore, the SAR values for PEG-[MLPG] $\left(217.8 \mathrm{~W} \mathrm{~g} \mathrm{Fe}^{-1}\right)$ and $\left[\mathrm{ML}_{\mathrm{PG}}\right]\left(204.6 \mathrm{~W} \mathrm{~g} \mathrm{Fe}^{-1}\right)$ were significantly greater than for $\left[\mathrm{ML}_{\mathrm{P}}\right](93.8 \mathrm{~W}$ $\mathrm{g} \mathrm{Fe}^{-1}$ ), indicating that colocalization of a GNS and IONs increased the SAR values more than two-fold. TEM analysis of PEG-[MLPG] before and after RF heating (Figure 3B) showed that RF heating caused the release of IONs and GNPs from the nanostructures. 

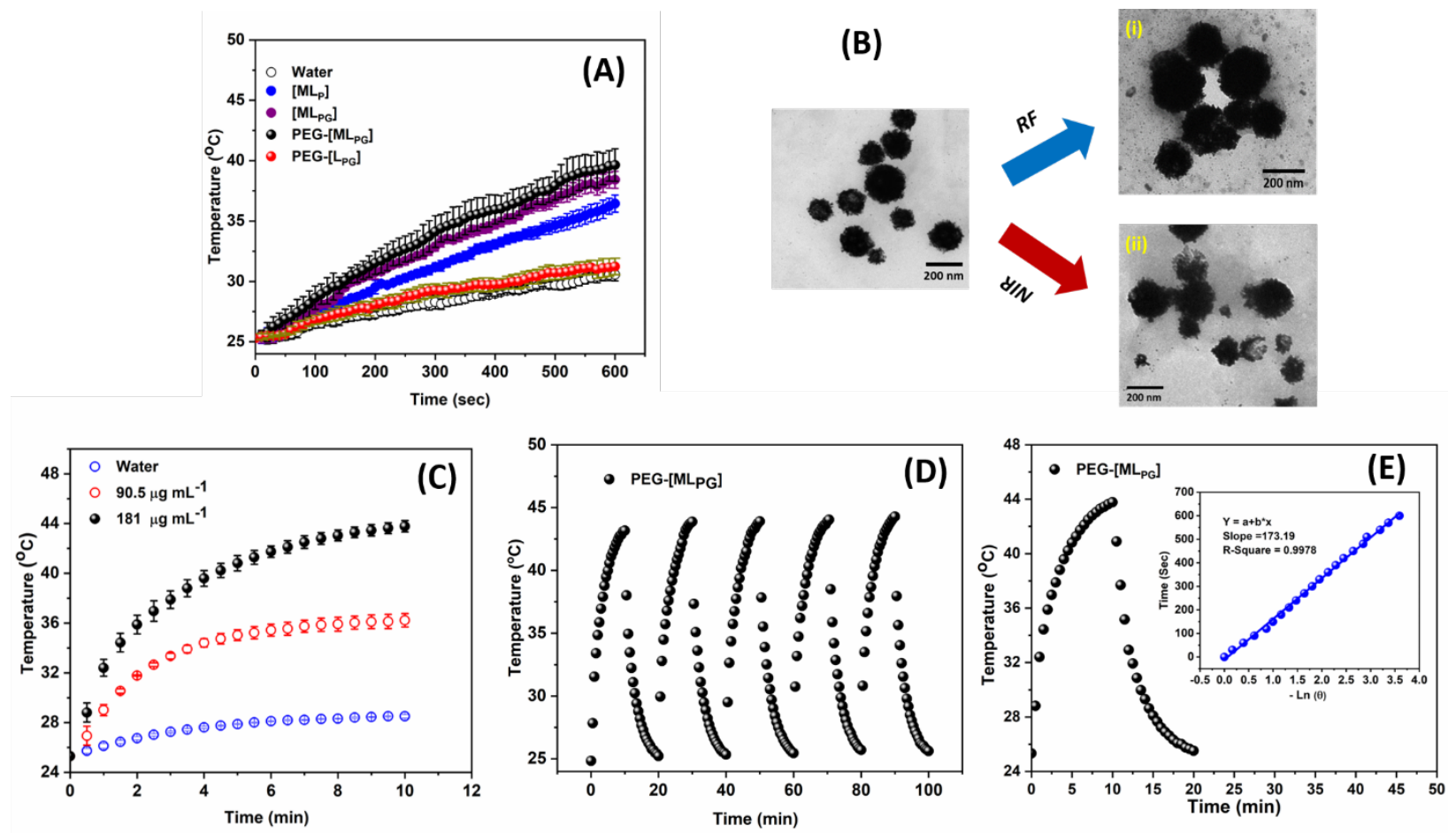

Figure 3. (A) RF heating for water (open white circle), [MLP] (blue), [MLPG] (purple), PEG[MLPG] (black), and PEG-[LPG (red) at $368 \mathrm{KHz}$ and $160 \mathrm{~A}$. The samples contained $376 \pm 93 \mu \mathrm{g}$ $\mathrm{mL}^{-1}$ Fe. (B) Electron micrograph of PEG-[MLPG] before and after RF or NIR stimulation. (C) Photothermal NIR heating of PEG-[MLPG] and water at a power density $3.5 \mathrm{~W} \mathrm{~cm}^{-2}$ and (D) temperature cycle stability of PEG-[MLPG] over 5 ON/OFF NIR cycles. (E) Temperature evolution of PEG-[MLPG] upon NIR laser irradiation for 10 min followed by cooling (Inset: cooling time as a function of $-\operatorname{Ln}(\theta))$.

\section{Photothermal Heating}

Photothermal heating of PEG-[MLPG] was examined with a $785 \mathrm{~nm}$ NIR laser diode source at a power density of $3.5 \mathrm{~W} \mathrm{~cm}^{-2}$ to determine the energy conversion efficiency (Figure $3 \mathrm{C}-\mathrm{E}$ ). $\Delta \mathrm{T}_{\max }$ was proportional to the gold concentration and, after subtracting the temperature rise due to the blank water sample, reached $15.6^{\circ} \mathrm{C}$ after $10 \mathrm{~min}$ (Figure 3C). To assess the photostability of 
PEG-[MLPG], five ON/OFF cycles of NIR stimuli (10 min ON and $10 \mathrm{~min}$ OFF; Figure 3D) were performed. The results (Figure 3C) show a consistent $\Delta \mathrm{T}_{\max }$, highlighting the stability of PEG$\left[\mathrm{ML}_{\mathrm{PG}}\right]$ for achieving successive photothermal treatments. The photothermal conversion efficiency of $46.4 \%$ is comparable with other gold nanoshells reported in the literature. ${ }^{25,53}$

\section{Drug Encapsulation Efficiency and Release}

The DOX encapsulation efficiency for [ML-DOX] was 43.7\%. PEG-No measurable DOX release was observed after polyelectrolyte coating or after gold nanoshell formation (results not shown), confirming that the structures retained their cargo through the assembly process. Cumulative DOX release was examined with or without external RF or NIR stimuli at $37^{\circ} \mathrm{C}$ and $\mathrm{pH} 7.4$ (Figure 4). Significant passive release (no RF) was observed for [ML-DOX] over 24 h. Comparatively, passive release for PEG-[MLPG-DOX] was less than $10 \%$, which can be attributed to the additional barrier properties of the GNS. When exposed to an RF field for the first 30 min of the experiment, PEG-[MLPG-DOX] released $25 \%$ of the DOX after 5 min and nearly $40 \%$ after $24 \mathrm{~h}$.

Increased DOX release was also observed following NIR stimulus. In this case, stimulus was applied periodically in an "ON/OFF" mode with NIR laser irradiation "ON" for 10 min intervals at $1 \mathrm{~h}, 3 \mathrm{~h}, 10 \mathrm{~h}$, and $22 \mathrm{~h}$. At each "ON" stimulus interval, there was an immediate release of DOX. When the stimulus was "OFF", DOX release decreased to a rate similar to the control sample without stimulus.

For both RF and NIR stimulus the increase in DOX release can be attributed to the combination of heat generation and physical disruption of the shell structure, both of which increased the effective shell permeability. As shown in Figures 3B, PEG-[ML $\left.{ }_{P G}-D O X\right]$ structures were deformed after RF or NIR stimulation, respectively. The cumulative DOX release was limited 
to less than $40 \%$ in both cases, despite partial shell disruption. This is attributed to the presence of polycation PLL, which likely trapped anionic DOX within the assemblies via electrostatic attraction.
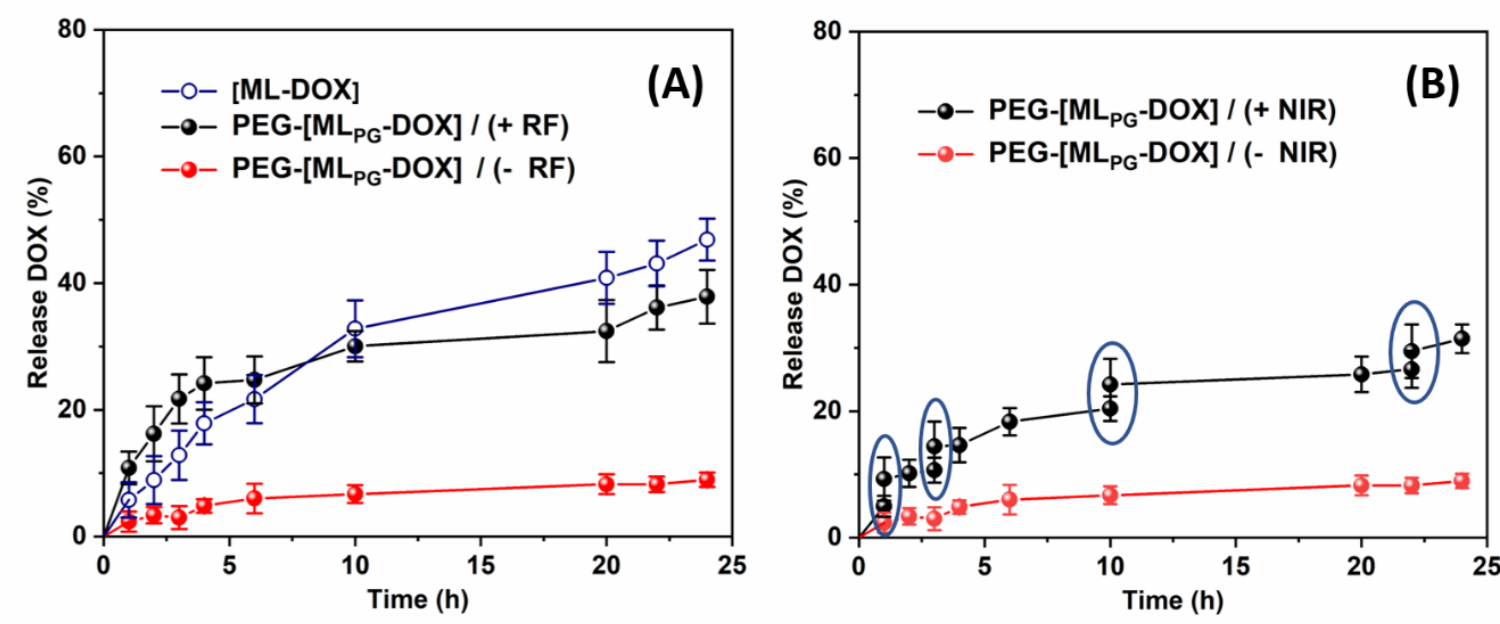

Figure 4. DOX release profile for PEG-[MLPG-DOX] (A) with or without RF treatment and (B) with or without laser at $37{ }^{\circ} \mathrm{C}$ and $\mathrm{pH}$ 7.4. RF stimulus was applied for the first $30 \mathrm{~min}$. NIR stimulus was applied for 10 min at $1 \mathrm{~h}, 3 \mathrm{~h}, 10 \mathrm{~h}$, and $22 \mathrm{~h}$ (circled increments; Figure 4B).

\section{Cytotoxicity}

There are few reports concerning the toxicity of magneto-plasmonic nanoparticles, particularly based on liposomal systems for cancer cell treatment. ${ }^{20,64}$ The cytotoxicity towards A549 cells was examined with and without RF or NIR stimulation (Figure 5A), with encapsulated DOX without stimulation (Figure 5B), and with combined stimulation and DOX release (Figure 5C) over $48 \mathrm{~h}$ incubation. Without encapsulated DOX or stimulation, [MLPG] (Figure 5A) and PEG-[MLPG] (Figure 5C) were not cytotoxic. However, cytotoxicity was observed with RF or NIR stimulation applied $4 \mathrm{~h}$ after the addition of PEG-[ML $\left.\mathrm{PG}_{\mathrm{P}}\right]$, confirming hypothermia treatment (Figure $5 \mathrm{~A}$ ). $\mathrm{RF}$ or NIR treatment alone did not impact cell viability (results not shown). 
The cytotoxicity of the PEG-[MLPG-DOX] and free DOX was examined as a function of DOX concentration. PEG-[MLPG-DOX] were toxic in a dose-dependent manner where cell viability decreased to $55.3 \%$ for encapsulated DOX at $6.7 \mu \mathrm{g} \mathrm{mL}^{-1}$. Cytotoxicity of free DOX was also dose-dependent at $48 \mathrm{~h}$ (Figure $5 \mathrm{~B}$ ) and greater than that of PEG-[ML $\left.\mathrm{PG}_{\mathrm{PG}}-\mathrm{DOX}\right]$ as it can freely diffuse into cells and is more bioavailable than when encapsulated and retained within the liposomes. ${ }^{38,48}$ A passive DOX release from PEG-[MLPG-DOX] of 10\% (Figure 4A) would yield an effective DOX dose of $0.67 \mu \mathrm{g} \mathrm{mL}^{-1}$. There is good agreement in the cell viabilities for free DOX at $0.67 \mu \mathrm{g} \mathrm{mL}^{-1}$ and the effective DOX dose, confirming that passive DOX release from PEG-[MLPG-DOX] is responsible for the cytotoxicity.

With DOX encapsulation coupled with RF or NIR stimulation, A549 cell viability decreased to $17.8 \%$ and $24.6 \%$ ( $\mathrm{p}<0.01$ relative to no stimulation) at an equivalent concentration of DOX $6.7 \mu \mathrm{g} \mathrm{mL}^{-1}$, respectively (Figure 5C). Free DOX at the same concentration led to a cell viability of $16 \%$, suggesting that the mechanism treatment could be the near-complete DOX release from the nanostructures via RF or NIR stimuli. However, if we consider that only a portion of DOX is released with RF or NIR exposure (Figure 4), the mechanism can be attributed to the combined effect of partial DOX release and RF or NIR hyperthermia.
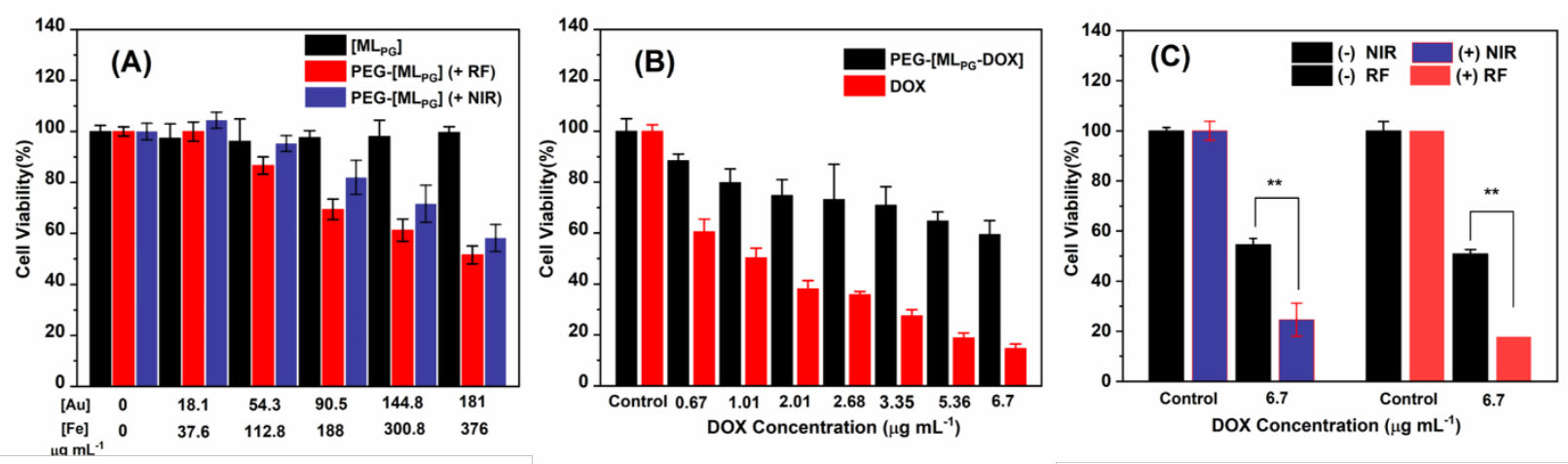

Figure 5. Cell viability of A549 cells treated with different formulations. (A) Cell exposed to [ML $\left.L_{P G}\right]$ and PEG-[MLPG] before and after RF or NIR stimulation. (B) Cells exposed to PEG- 
$\left[\mathrm{ML}_{\mathrm{PG}}-\mathrm{DOX}\right]$ and free DOX at different concentration of DOX after $48 \mathrm{~h}$ incubation. (C) Cell exposed to PEG-[MLPG-DOX] with RF or NIR stimulation.

\section{Cellular Uptake and Stimuli-triggered Intracellular DOX Release}

Nanoparticle uptake was examined by confocal microscopy. Free DOX was observed in both the cytosol and nucleus (Figure 6A, top). However, DOX was only observed in the cytosol when encapsulated within PEG-[MLPG-DOX] (Figure 6A, bottom). Hence, without stimulation DOX

remains trapped within the internalized nanostructures. ICP-MS was used to quantify the extent of PEG-[MLPG-DOX] uptake at incubation times of $2 \mathrm{~h}, 4 \mathrm{~h}$, and $6 \mathrm{~h}$. Based on the Au and Fe

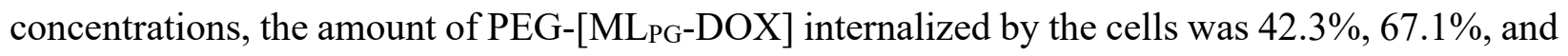
$77.8 \%$, respectively.

Direct evidence of triggered intracellular release via RF or NIR stimulation was obtained by microscopy, complimenting the cell viability studies. After RF or NIR stimulation, DOX was co-localized with DAPI (blue) in the nucleus, in addition to being present in the cytosol (Figure 6B). This confirms that stimulation led to the release of DOX, which then entered the nucleus and intercalated within DNA to cause cytotoxicity. 


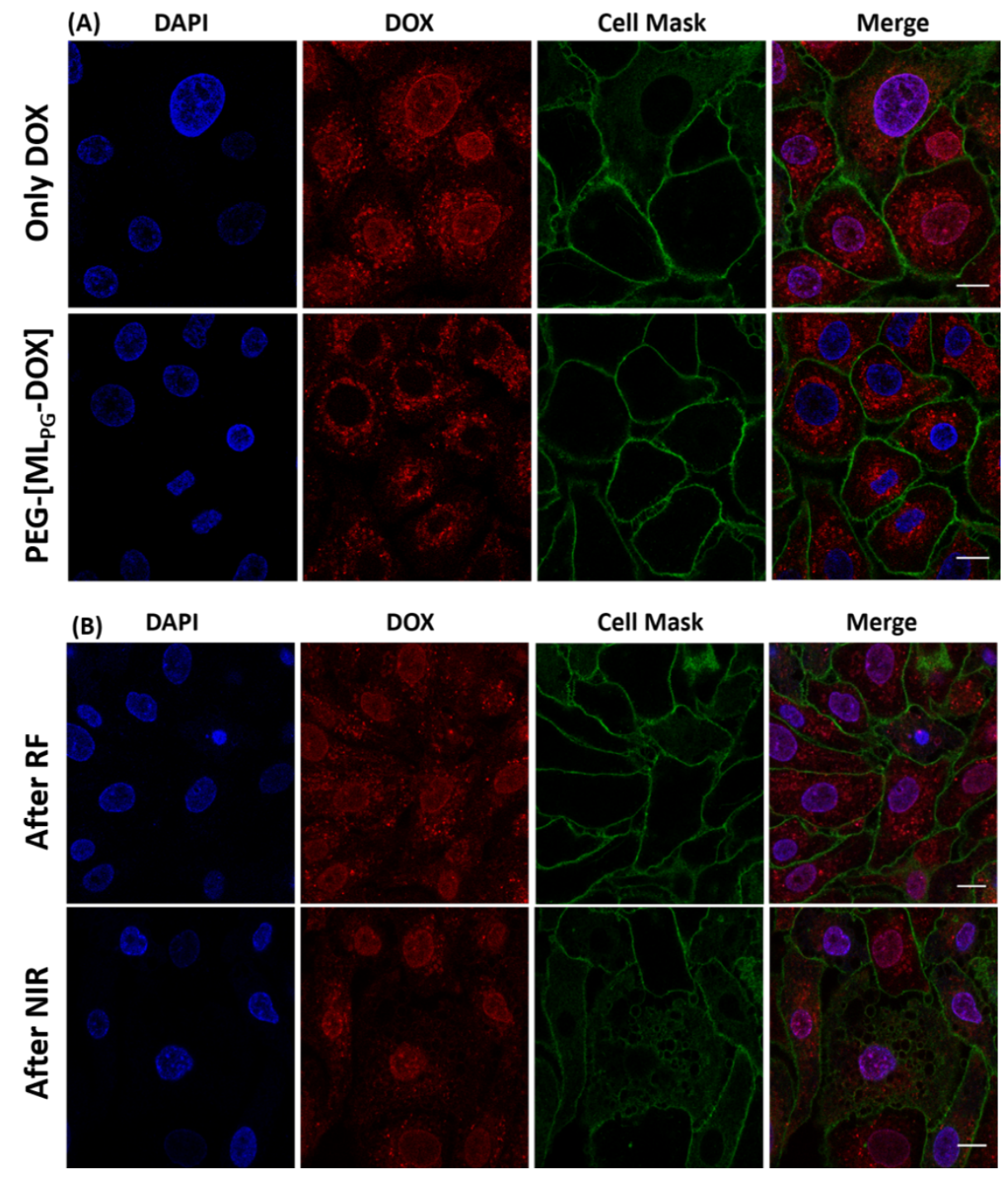

Figure 6. (A) Confocal microscopy images of A549 cells incubated with (A) free DOX and PEG[ML $\left.\mathrm{MG}_{\mathrm{PG}}-\mathrm{DOX}\right]$ and with (B) A549 cells incubated with PEG-[ML $\left.{ }_{\mathrm{PG}}-\mathrm{DOX}\right]$ after RF or NIR laser irradiation. Blue, green, and red emissions indicate DAPI, cell mask, and DOX, respectively (scale bar reflects $10 \mu \mathrm{m}$ and is common to all images).

\section{CONCLUSIONS}

We have successfully developed liposomal-based magneto-plasmonic core-shell multifunctional nanostructures capable of triggered, intracellular drug release using self-assembled templates. The 
templates were coated with a polycation that served two functions - to facilitate gold nanoshell formation by enriching the interface with gold anion and to strengthen the structure against spontaneous drug leakage. This approach provides a versatile templating technique for creating complex core-shell nanostructures. Without the external stimuli the structures retained their DOX cargo and were capable of delivering it intracellularly. Once inside the cells, both RF and NIR laser stimuli caused the structures to heat, deform, and release the encapsulated DOX. Similar cytotoxicity was observed for intracellularly-triggered DOX release and the free DOX treatment at an equivalent DOX concentration. Additional studies are needed to determine the intracellular fate of the nanostructures before and after RF or NIR stimulation, the effect of simultaneous RF and NIR exposure, and the ability to incorporate the targeting ligands.

\section{AUTHOR INFORMATION}

Corresponding Author

*Tel.: +1-401-874-9518

*Fax: +1-401-874-4689

*E-mail: gbothun@uri.edu

\section{ORCID}

Geoffrey D. Bothun: 0000-0002-7513-2417

Animesh Pan: 0000-0002-9222-687X

\section{Notes}

The authors declare no competing financial interests.

\section{ACKNOWLEDGEMENTS}

This research was supported by the National Science Foundation under Grant CBET-1337061. Additional resources were provided by the Rhode Island Consortium for Nanoscience and Nanotechnology, which is supported in part by the National Science Foundation under the 
Established Program to Stimulate Competitive Research (EPSCoR) Cooperative Agreement OIA1655221, and through core facilities supported by the Rhode Island Institutional Development Award (IDeA) Network of Biomedical Research Excellence from the National Institute of General Medical Sciences of the National Institutes of Health under grant number P20GM103430.

\section{References}

(1) Liu, Y.; Zhen, W.; Jin, L.; Zhang, S.; Sun, G.; Zhang, T.; Xu, X.; Song, S.; Wang, Y.; Liu, J. All-in-One Theranostic Nanoagent with Enhanced Reactive Oxygen Species Generation and Modulating Tumor Microenvironment Ability for Effective Tumor Eradication. ACS Nano 2018, 12 (5), 4886-4893.

(2) Hua, X.-W.; Bao, Y.-W.; Zeng, J.; Wu, F.-G. Ultrasmall All-In-One Nanodots Formed via Carbon Dot-Mediated and Albumin-Based Synthesis: Multimodal Imaging-Guided and Mild Laser-Enhanced Cancer Therapy. ACS Appl. Mater. Interfaces 2018, 10 (87), 4207742087.

(3) Sato, Y.; Hatakeyama, H.; Sakurai, Y.; Hyodo, M.; Akita, H.; Harashima, H. A PHSensitive Cationic Lipid Facilitates the Delivery of Liposomal SiRNA and Gene Silencing Activity in Vitro and in Vivo. J. Controlled Release 2012, 163 (3), 267-276.

(4) Huang, P.; Lin, J.; Wang, X.; Wang, Z.; Zhang, C.; He, M.; Wang, K.; Chen, F.; Li, Z.; Shen, G. Light-Triggered Theranostics Based on Photosensitizer-Conjugated Carbon Dots for Simultaneous Enhanced-Fluorescence Imaging and Photodynamic Therapy. Adv. Mater. 2012, 24 (37), 5104-5110.

(5) Li, L.; Fu, S.; Chen, C.; Wang, X.; Fu, C.; Wang, S.; Guo, W.; Yu, X.; Zhang, X.; Liu, Z.; et al. Microenvironment-Driven Bioelimination of Magnetoplasmonic Nanoassemblies and Their Multimodal Imaging-Guided Tumor Photothermal Therapy. ACS Nano 2016, 10 (7), 7094-7105.

(6) Bao, G.; Mitragotri, S.; Tong, S. Multifunctional Nanoparticles for Drug Delivery and Molecular Imaging. Annu. Rev. Biomed. Eng. 2013, 15 (1), 253-282.

(7) Chen, O.; Riedemann, L.; Etoc, F.; Herrmann, H.; Coppey, M.; Barch, M.; Farrar, C. T.; Zhao, J.; Bruns, O. T.; Wei, H. Magneto-Fluorescent Core-Shell Supernanoparticles. Nat. Commun. 2014, 5 (1), 1-16.

(8) Yao, J.; Yang, M.; Duan, Y. Chemistry, Biology, and Medicine of Fluorescent Nanomaterials and Related Systems: New Insights into Biosensing, Bioimaging, Genomics, Diagnostics, and Therapy. Chem. Rev. 2014, 114 (12), 6130-6178.

(9) Bigall, N. C.; Parak, W. J.; Dorfs, D. Fluorescent, Magnetic and Plasmonic-Hybrid Multifunctional Colloidal Nano Objects. Nano Today 2012, 7 (4), 282-296.

(10) Hao, R.; Xing, R.; Xu, Z.; Hou, Y.; Gao, S.; Sun, S. Synthesis, Functionalization, and Biomedical Applications of Multifunctional Magnetic Nanoparticles. Adv. Mater. 2010, 22 (25), 2729-2742. 
(11) Jain, P. K.; Huang, X.; El-Sayed, I. H.; El-Sayed, M. A. Noble Metals on the Nanoscale: Optical and Photothermal Properties and Some Applications in Imaging, Sensing, Biology, and Medicine. Acc. Chem. Res. 2008, 41 (12), 1578-1586.

(12) Ghosh Chaudhuri, R.; Paria, S. Core/Shell Nanoparticles: Classes, Properties, Synthesis Mechanisms, Characterization, and Applications. Chem. Rev. 2012, 112 (4), 2373-2433.

(13) Li, W.-P.; Liao, P.-Y.; Su, C.-H.; Yeh, C.-S. Formation of Oligonucleotide-Gated Silica Shell-Coated $\mathrm{Fe}_{3} \mathrm{O}_{4}$-Au Core-Shell Nanotrisoctahedra for Magnetically Targeted and Near-Infrared Light-Responsive Theranostic Platform. J. Am. Chem. Soc. 2014, 136 (28), $10062-10075$.

(14) Wang, H.; Cao, G.; Gai, Z.; Hong, K.; Banerjee, P.; Zhou, S. Magnetic/NIR-Responsive Drug Carrier, Multicolor Cell Imaging, and Enhanced Photothermal Therapy of Gold Capped Magnetite-Fluorescent Carbon Hybrid Nanoparticles. Nanoscale 2015, 7 (17), 7885-7895.

(15) Chatterjee, K.; Sarkar, S.; Jagajjanani Rao, K.; Paria, S. Core/Shell Nanoparticles in Biomedical Applications. Adv. Colloid Interface Sci. 2014, 209, 8-39.

(16) Li, C.; Chen, T.; Ocsoy, I.; Zhu, G.; Yasun, E.; You, M.; Wu, C.; Zheng, J.; Song, E.; Huang, C. Z. Gold-Coated Fe3O4 Nanoroses with Five Unique Functions for Cancer Cell Targeting, Imaging and Therapy. Adv. Funct. Mater. 2014, 24 (12), 1772-1780.

(17) Levin, C. S.; Hofmann, C.; Ali, T. A.; Kelly, A. T.; Morosan, E.; Nordlander, P.; Whitmire, K. H.; Halas, N. J. Magnetic-Plasmonic Core-Shell Nanoparticles. ACS Nano 2009, 3 (6), 1379-1388.

(18) Jin, Y.; Jia, C.; Huang, S.-W.; O’Donnell, M.; Gao, X. Multifunctional Nanoparticles as Coupled Contrast Agents. Nat. Commun. 2010, 1 (47), 1-17.

(19) Jin, Y. Multifunctional Compact Hybrid Au Nanoshells: A New Generation of Nanoplasmonic Probes for Biosensing, Imaging, and Controlled Release. Acc. Chem. Res. 2014, 47 (1), 138-148.

(20) Tomitaka, A.; Arami, H.; Raymond, A.; Yndart, A.; Kaushik, A.; Jayant, R. D.; Takemura, Y.; Cai, Y.; Toborek, M.; Nair, M. Development of Magneto-Plasmonic Nanoparticles for Multimodal Image-Guided Therapy to the Brain. Nanoscale 2017, 9 (2), 764-773.

(21) Tomitaka, A.; Arami, H.; Huang, Z.; Raymond, A.; Rodriguez, E.; Cai, Y.; Febo, M.; Takemura, Y.; Nair, M. Hybrid Magneto-Plasmonic Liposomes for Multimodal ImageGuided and Brain-Targeted HIV Treatment. Nanoscale 2017, 10 (1), 184-194.

(22) Pick, H.; Alves, A. C.; Vogel, H. Single-Vesicle Assays Using Liposomes and Cell-Derived Vesicles: From Modeling Complex Membrane Processes to Synthetic Biology and Biomedical Applications. Chem. Rev. 2018, 118 (18), 8598-8654.

(23) Kashcooli, Y.; Park, K.; Bose, A.; Greenfield, M.; Bothun, G. D. Patchy Layersomes Formed by Layer-by-Layer Coating of Liposomes with Strong Biopolyelectrolytes. Biomacromolecules 2016, 17 (11), 3838-3844.

(24) Abbasi, A.; Park, K.; Bose, A.; Bothun, G. D. Near-Infrared Responsive Gold-Layersome Nanoshells. Langmuir 2017, 33 (21), 5321-5327.

(25) Wang, M.; Liu, Y.; Zhang, X.; Luo, L.; Li, L.; Xing, S.; He, Y.; Cao, W.; Zhu, R.; Gao, D. Gold Nanoshell Coated Thermo-PH Dual Responsive Liposomes for Resveratrol Delivery and Chemo-Photothermal Synergistic Cancer Therapy. J. Mater. Chem. B 2017, 5 (11), 2161-2171.

(26) Wang, M.; Li, L.; Zhang, X.; Liu, Y.; Zhu, R.; Liu, L.; Fang, Y.; Gao, Z.; Gao, D. Magnetic Resveratrol Liposomes as a New Theranostic Platform for Magnetic Resonance Imaging 
Guided Parkinson's Disease Targeting Therapy. ACS Sustain. Chem. Eng. 2018, 6 (12), 17124-17133.

(27) Salvatore, A.; Montis, C.; Berti, D.; Baglioni, P. Multifunctional Magnetoliposomes for Sequential Controlled Release. ACS Nano 2016, 10 (8), 7749-7760.

(28) Aizik, G.; Waiskopf, N.; Agbaria, M.; Levi-Kalisman, Y.; Banin, U.; Golomb, G. Delivery of Liposomal Quantum Dots via Monocytes for Imaging of Inflamed Tissue. ACS Nano 2017, 11 (3), 3038-3051.

(29) Preiss, M. R.; Hart, A.; Kitchens, C.; Bothun, G. D. Hydrophobic Nanoparticles Modify the Thermal Release Behavior of Liposomes. J. Phys. Chem. B 2017, 121 (19), 5040-5047.

(30) Di Corato, R.; Béalle, G.; Kolosnjaj-Tabi, J.; Espinosa, A.; Clément, O.; Silva, A. K. A.; Ménager, C.; Wilhelm, C. Combining Magnetic Hyperthermia and Photodynamic Therapy for Tumor Ablation with Photoresponsive Magnetic Liposomes. ACS Nano 2015, 9 (3), 2904-2916.

(31) Zhao, Y.; Dai, X.; Wei, X.; Yu, Y.; Chen, X.; Zhang, X.; Li, C. Near-Infrared LightActivated Thermosensitive Liposomes as Efficient Agents for Photothermal and Antibiotic Synergistic Therapy of Bacterial Biofilm. ACS Appl. Mater. Interfaces 2018, 10 (17), $14426-14437$.

(32) Preiss, M. R.; Bothun, G. D. Stimuli-Responsive Liposome-Nanoparticle Assemblies. Expert Opin. Drug Deliv. 2011, 8 (8), 1025-1040.

(33) Chen, Y.; Bose, A.; Bothun, G. D. Controlled Release from Bilayer-Decorated Magnetoliposomes via Electromagnetic Heating. ACS Nano 2010, 4 (6), 3215-3221.

(34) Chauhan, D. S.; Prasad, R.; Devrukhkar, J.; Selvaraj, K.; Srivastava, R. Disintegrable NIR Light Triggered Gold Nanorods Supported Liposomal Nanohybrids for Cancer Theranostics. Bioconjug. Chem. 2018, 29 (5), 1510-1518.

(35) Agarwal, A.; Mackey, M. A.; El-Sayed, M. A.; Bellamkonda, R. V. Remote Triggered Release of Doxorubicin in Tumors by Synergistic Application of Thermosensitive Liposomes and Gold Nanorods. ACS Nano 2011, 5 (6), 4919-4926.

(36) Ou, Y.-C.; Webb, J. A.; Faley, S.; Shae, D.; Talbert, E. M.; Lin, S.; Cutright, C. C.; Wilson, J. T.; Bellan, L. M.; Bardhan, R. Gold Nanoantenna-Mediated Photothermal Drug Delivery from Thermosensitive Liposomes in Breast Cancer. ACS Omega 2016, 1 (2), 234-243.

(37) Rengan, A. K.; Bukhari, A. B.; Pradhan, A.; Malhotra, R.; Banerjee, R.; Srivastava, R.; De, A. In Vivo Analysis of Biodegradable Liposome Gold Nanoparticles as Efficient Agents for Photothermal Therapy of Cancer. Nano Lett. 2015, 15 (2), 842-848.

(38) Nguyen, V. D.; Min, H.-K.; Kim, C.-S.; Han, J.; Park, J.-O.; Choi, E. Folate ReceptorTargeted Liposomal Nanocomplex for Effective Synergistic Photothermal-Chemotherapy of Breast Cancer in Vivo. Colloids Surf. B Biointerfaces 2019, 173, 539-548.

(39) M. Vargas, K.; Shon, Y.-S. Hybrid Lipid-Nanoparticle Complexes for Biomedical Applications. J. Mater. Chem. B 2019, 7 (5), 695-708.

(40) Børresen, B.; Henriksen, J. R.; Clergeaud, G.; Jørgensen, J. S.; Melander, F.; Elema, D. R.; Szebeni, J.; Engelholm, S. A.; Kristensen, A. T.; Kjær, A. Theranostic Imaging May Vaccinate against the Therapeutic Benefit of Long Circulating PEGylated Liposomes and Change Cargo Pharmacokinetics. ACS Nano 2018, 12 (11), 11386-11398.

(41) Guimarães, P. P. G.; Gaglione, S.; Sewastianik, T.; Carrasco, R. D.; Langer, R.; Mitchell, M. J. Nanoparticles for Immune Cytokine TRAIL-Based Cancer Therapy. ACS Nano 2018, $12(2), 912-931$. 
(42) Du, B.; Han, S.; Li, H.; Zhao, F.; Su, X.; Cao, X.; Zhang, Z. Multi-Functional Liposomes Showing Radiofrequency-Triggered Release and Magnetic Resonance Imaging for Tumor Multi-Mechanism Therapy. Nanoscale 2015, 7 (12), 5411-5426.

(43) Ren, L.; Chen, S.; Li, H.; Zhang, Z.; Ye, C.; Liu, M.; Zhou, X. MRI-Visible Liposome Nanovehicles for Potential Tumor-Targeted Delivery of Multimodal Therapies. Nanoscale 2015, 7 (30), 12843-12850.

(44) Amstad, E.; Kohlbrecher, J.; Müller, E.; Schweizer, T.; Textor, M.; Reimhult, E. Triggered Release from Liposomes through Magnetic Actuation of Iron Oxide Nanoparticle Containing Membranes. Nano Lett. 2011, 11 (4), 1664-1670.

(45) Prasad, R.; Yadav, A. S.; Gorain, M.; Chauhan, D. S.; Kundu, G. C.; Srivastava, R.; Selvaraj, K. Graphene Oxide Supported Liposomes as Red Emissive Theranostics for Phototriggered Tissue Visualization and Tumor Regression. ACS Appl. Bio Mater. 2019, 2 (8), 3312-3320.

(46) Huang, Y.; Hemmer, E.; Rosei, F.; Vetrone, F. Multifunctional Liposome Nanocarriers Combining Upconverting Nanoparticles and Anticancer Drugs. J. Phys. Chem. B 2016, 120 (22), 4992-5001.

(47) Luo, L.; He, H.; Li, C.; He, Y.; Hao, Z.; Wang, S.; Zhao, Q.; Liu, Z.; Gao, D. Near-Infrared Responsive Bimetallic Nanovesicles for Enhanced Synergistic Chemophotothermal Therapy. ACS Biomater. Sci. Eng. 2019, 5 (3), 1321-1331.

(48) Shen, S.; Huang, D.; Cao, J.; Chen, Y.; Zhang, X.; Guo, S.; Ma, W.; Qi, X.; Ge, Y.; Wu, L. Magnetic Liposomes for Light-Sensitive Drug Delivery and Combined PhotothermalChemotherapy of Tumors. J. Mater. Chem. B 2019, 7 (7), 1096-1106.

(49) Troutman, T. S.; Barton, J. K.; Romanowski, M. Biodegradable Plasmon Resonant Nanoshells. Adv. Mater. 2008, 20 (13), 2604-2608.

(50) Leung, S. J.; Romanowski, M. NIR-Activated Content Release from Plasmon Resonant Liposomes for Probing Single-Cell Responses. ACS Nano 2012, 6 (11), 9383-9391.

(51) Rengan, A. K.; Bukhari, A. B.; Pradhan, A.; Malhotra, R.; Banerjee, R.; Srivastava, R.; De, A. In Vivo Analysis of Biodegradable Liposome Gold Nanoparticles as Efficient Agents for Photothermal Therapy of Cancer. Nano Lett. 2015, 15 (2), 842-848.

(52) Rengan, A. K.; Jagtap, M.; De, A.; Banerjee, R.; Srivastava, R. Multifunctional Gold Coated Thermo-Sensitive Liposomes for Multimodal Imaging and Photo-Thermal Therapy of Breast Cancer Cells. Nanoscale 2013, 6 (2), 916-923.

(53) Liu, Y.; Zhang, X.; Liu, Z.; Wang, L.; Luo, L.; Wang, M.; Wang, Q.; Gao, D. Gold Nanoshell-Based Betulinic Acid Liposomes for Synergistic Chemo-Photothermal Therapy. Nanomedicine Nanotechnol. Biol. Med. 2017, 13 (6), 1891-1900.

(54) Torrico Guzmán, E. A.; Sun, Q.; Meenach, S. A. Development and Evaluation of PaclitaxelLoaded Aerosol Nanocomposite Microparticles and Their Efficacy Against Air-Grown Lung Cancer Tumor Spheroids. ACS Biomater. Sci. Eng. 2019, doi.org/10.1021/acsbiomaterials.9b00947.

(55) Szoka, F.; Papahadjopoulos, D. Procedure for Preparation of Liposomes with Large Internal Aqueous Space and High Capture by Reverse-Phase Evaporation. Proc. Natl. Acad. Sci. U. S. A. 1978, 75 (9), 4194-4198.

(56) Béalle, G.; Di Corato, R.; Kolosnjaj-Tabi, J.; Dupuis, V.; Clément, O.; Gazeau, F.; Wilhelm, C.; Ménager, C. Ultra Magnetic Liposomes for MR Imaging, Targeting, and Hyperthermia. Langmuir 2012, 28 (32), 11834-11842. 
(57) Natividad, E.; Castro, M.; Mediano, A. Adiabatic Magnetothermia Makes Possible the Study of the Temperature Dependence of the Heat Dissipated by Magnetic Nanoparticles under Alternating Magnetic Fields. Appl. Phys. Lett. 2011, 98 (24), 243119.

(58) Tian, Q.; Jiang, F.; Zou, R.; Liu, Q.; Chen, Z.; Zhu, M.; Yang, S.; Wang, J.; Wang, J.; Hu, J. Hydrophilic Cu9S5 Nanocrystals: A Photothermal Agent with a 25.7\% Heat Conversion Efficiency for Photothermal Ablation of Cancer Cells in Vivo. ACS Nano 2011, 5 (12), 9761-9771.

(59) Huang, P.; Lin, J.; Li, W.; Rong, P.; Wang, Z.; Wang, S.; Wang, X.; Sun, X.; Aronova, M.; Niu, G. Biodegradable Gold Nanovesicles with an Ultrastrong Plasmonic Coupling Effect for Photoacoustic Imaging and Photothermal Therapy. Angew. Chem. Int. Ed. 2013, 52 (52), $13958-13964$.

(60) Kim, H.-C.; Kim, E.; Jeong, S. W.; Ha, T.-L.; Park, S.-I.; Lee, S. G.; Lee, S. J.; Lee, S. W. Magnetic Nanoparticle-Conjugated Polymeric Micelles for Combined Hyperthermia and Chemotherapy. Nanoscale 2015, 7 (39), 16470-16480.

(61) Hervault, A.; Thanh, N. T. K. Magnetic Nanoparticle-Based Therapeutic Agents for Thermo-Chemotherapy Treatment of Cancer. Nanoscale 2014, 6 (20), 11553-11573.

(62) Chen, H.-J.; Wen, D. Experimental Study of Electromagnetic Heating of Gold Nanoparticle Dispersions at $200 \mathrm{KHz}$. Nanomed. 2012, 8 (2), 215-222.

(63) Park, S.-I.; Chung, S.-H.; Kim, H.-C.; Lee, S. G.; Lee, S. J.; Kim, H.; Kim, H.; Jeong, S. W. Prolonged Heating of Fe3O4-Au Hybrid Nanoparticles in a Radiofrequency Solenoid Coil. Colloids Surf. Physicochem. Eng. Asp. 2018, 538, 304-309.

(64) Khosroshahi, M. E. In-Vitro Application of Doxorubicin Loaded Magnetoplasmonic Thermosensitive Liposomes for Laser Hyperthermia and Chemotherapy of Breast Cancer. J. Nanomedicine Nanotechnol. 2015, 06 (04), 1-9. 
Table of Contents (TOC):

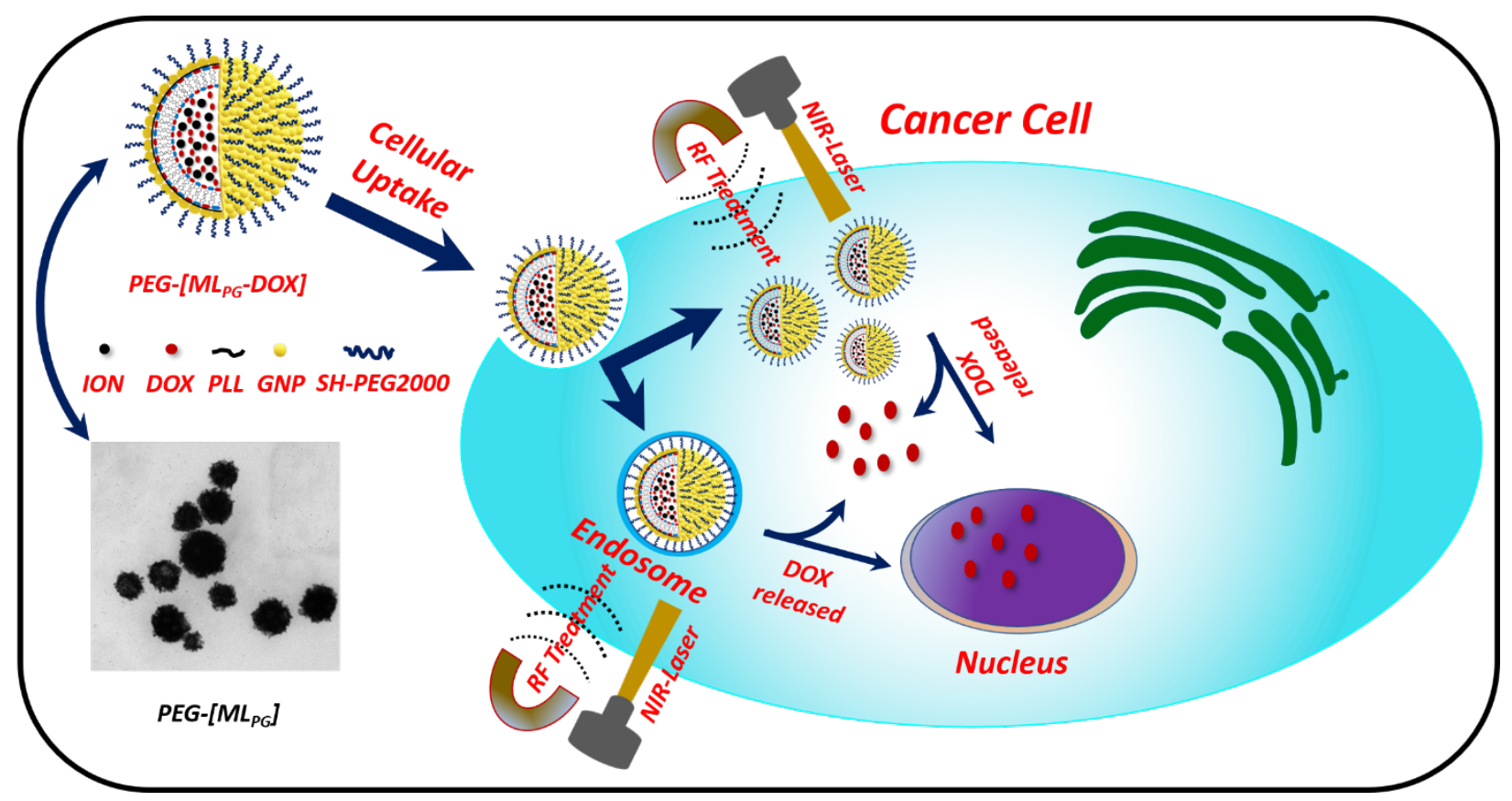

